\title{
A Typology for a Social Justice Approach to Assessment: Learning from Universal Design and Culturally Sustaining Pedagogy
}

\section{Pauline Hanesworth [Corresponding author]}

Academic Practice and Professional Development, The Higher Education Academy, Innovation Way, York Science Park, Heslington, York, YO10 5BR, UK, pauline.hanesworth@heacademy.ac.uk

\section{Seán Bracken}

Institute of Education, University of Worcester, Worcester, Henwick Grove, WR2 6AJ, UK, s.bracken@worc.ac.uk

\section{Sam Elkington}

Academic Practice and Professional Development, The Higher Education Academy, Innovation Way, York Science Park, Heslington, York, YO10 5BR, UK, samuel.elkington@heacademy.ac.uk

Pauline Hanesworth is an Academic Lead for Equality and Diversity and the TEF at the Higher Education Academy. Her research interests include embedding equality and diversity in the curriculum, social justice approaches to education, the relationship between oral narratives and individual and collective identity, and values-based pedagogies.

Seán Bracken is a Principal Lecturer in Education at the University of Worcester. His research interests include inclusive leadership in higher education; he is particularly interested in whole organisational change management processes that are cognisant of marginalised student cohorts. Sean is currently course leader for the National Award SENCO.

Sam Elkington is an Academic Lead for Assessment and Flexible Pedagogy at the Higher Education Academy. His research interests centre on the harnessing of creativity for the enhancement of academic engagement in higher education communities, and unpacking the relationship between openness, inclusivity, and alternative pedagogies.

Abstract word count: 145 words.

Article, including headings but excluding references, word count: 6,601 words. 


\title{
A Typology for a Social Justice Approach to Assessment: Learning from Universal Design and Culturally Sustaining Pedagogy
}

\begin{abstract}
This paper aims to provide a tentative roadmap for ensuring that higher education policy makers and practitioners are apprised of what might be done to advance a concept of socially just assessment praxis. It extends current thinking around the notion of social justice approaches to assessment by further developing the conceptual framework proposed in McArthur's recent work (2016). It does so by extending understandings of how a socially just perspective might be realised. Drawing upon recent conceptual developments within both Universal Design for Learning (UDL) and Culturally Sustaining Pedagogy (CSP), the paper proposes a typology for praxis and organisational change. Crucially, this typology focuses upon enhancing learning outcomes for all learners, but it is particularly concerned with enhancing educational experiences and learning outcomes for students that have been systematically marginalised by the normative procedural practices that have traditionally informed the nature of supposedly objective assessment.
\end{abstract}

Keywords: social justice; assessment and feedback; universal design for learning; culturally sustaining pedagogy; equality and diversity

\section{The current contextual impetus}

Assessment in UK higher education is neither value-neutral nor culture-free. It is a social construct: a practice and process arising from specific historical, social and cultural loci through and in which specific values are reflected and enshrined (McArthur 2016; Leathwood 2005; Stowell 2004; Filer 2000). For example, as Leathwood (2005, 316) argues, we have a current assessment system in which the predominantly white, male, middle-class, Western values of objectivity and individualism are lauded as markers of good work, rendering other markers of good practice - ones that are more prominent in other groups and cultures such as subjectivity and collaboration/collectivism - lesser indicators of intellectualism. Consider too the elevation of written linguistic capabilities over that of the oral (Lynch and Baker 2005) 
or of rational thought over emotional understanding (Hodkinson 2005).

It is not just values that are hierarchised in this system: so too is knowledge. Here we refer not just to the hierarchising of disciplines (Bourdieu 1988), but also to the hierarchising and prioritising of knowledge within that discipline. Assessment is predominantly selective: in its current dominant form, it is unable to cover the entirety of disciplinary or curriculum content. By selecting assessment content, educators are communicating, subconsciously, what is important - and more importantly, what is not - within their field. This is reflected for example in the common student refrain, 'do we need to know this for the assessment?'

Assessment is also a disciplinary construct: what, how and why we assess are products of disciplinary norms. Becoming attached to the discipline at a certain point in its evolution, assessment practices, through habitual and unquestioned use, become legitimised and seen as inextricable from disciplinary praxis (Hanesworth 2017; Gunn, Morrison, and Hanesworth 2015; Hatton 2012; Atkinson 2002). Atkinson (2002, $121-$ 124) uses the crit in the discipline of art as an example: having become a disciplinary or pedagogised - norm, the crit has become synonymous with studying art. In its normatisation, it consequently marginalises and even excludes certain students and groups for whom such an assessment method is both inaccessible and an unfeasible way in which to best evidence their learning.

Finally, assessment is indivisible from individual value judgements. No matter the structures and processes put in place, assessments are designed and evaluated by humans, with all their complex socio-cultural backgrounds, educational experiences, and intellectual and personal values (Malouff and Thorsteinsson 2016; Ryan and Viete 2009; Leathwood 2005; Stowell 2004). Ryan and Viete (2009, 304-305) illustrate how this can affect the assessment process. Referencing Litowitz (1993), they illustrate how 
academics can unconsciously conflate proof of learning with a learner becoming more like them: an assessment is judged to have value because it approximates the style (in language, in content, in tone) of the individual making the judgement rather than because of its intrinsic quality.

Thus, within its procedures, structures and systems, assessment codifies cultural, disciplinary and individual norms, values and knowledge hierarchies. Moreover, it inculcates these within the learner: to perform well in assessment, learners must adhere to these unconscious rules and value systems, continuously replicating them, and, eventually, internalising them. For those to whom these norms, values and knowledge hierarchies are unfamiliar or different to those central to their own cultural and social habitus and individual identities, a disconnect occurs: their habitus and identity are not recognised by that of the dominant assessment procedures and practices, implying their lack of value. This can lead to apathy, alienation and self-disqualification, to resistance and advocacy for change, or to assimilation to the norm (Gunn, Morrison and Hanesworth 2015, 40-41). Yet, there is, as Hockings (2010, 21) argues, little evidence of universities adapting their assessments to cater for diverse student cohorts with instead an emphasis on students themselves having to adapt to their university's dominant assessment styles.

In its crudest form, this is made manifest in average group differences in assessment performance and satisfaction. For example, in attainment and assessment satisfaction gaps between different ethnicities (ECU 2016, 110-145; MountfordZimdars et al. 2015, 14-17) and in attainment, retention and assessment satisfaction gaps between students with declared disabilities and those without (ECU 2016, 74-109; Mountford-Zimdars et al. 2015, 17-19). However, as we explore further below, we must be careful to avoid tendencies towards essentialising group and individual 
experiences of and responses to assessment since this can lead to misdirected deficit notions of difference. This occurs, for instance, when the focus on redressing inequities of assessment outcomes lies solely on an erroneously homogenised subset of learners (for example, BME students, disabled students, first generation, or white working class students) rather than the systematic processes underpinning practice.

In this paper, drawing on the concepts of Universal Design for Learning and Culturally Sustaining Pedagogy, we propose an approach to assessment, based on social justice theory, which aims to tackle the inhibiting effects of current systemic inequities in assessment outcomes, especially as experienced among minoritised groups. We acknowledge that the approach outlined is but one that could be taken under the umbrella of social justice, tending to actions predicated on tackling societal (read assessment) norms, redressing cultural (and educational) dominances and moving to true partnership. In so doing, we fall shy of approaches to social justice that look to dismantle systems of oppression, shatter dominant ideologies and build participatory democracies. That is not to say that we do not believe that the latter is something to which the higher education sector should be aiming. Rather, it is to say that this latter approach to social justice is beyond the scope of this paper, though hopefully something to which we can build with the approach articulated herein perhaps being but one of the stepping stones to this ultimate form. To better understand the approach we propose, we first seek to clarify the relationships between assessment and social justice as articulated by previous scholars.

\section{Social justice and assessment}

A social justice approach - in its broadest sense - to assessment is becoming increasingly recognised as a potential way forward for the sector (McArthur 2016; Nguyen and Walker 2015; Cazden 2012; Hockings 2010; Stowell 2004). However, 
there are differences in the ways in which this may be articulated by scholars. Hockings (2010, 2) argues that one such approach lays emphasis upon strengthening accessibility and learning outcomes for all students and that this 'embraces a wide range of differences and explores their effects on individual learning.' Cazden (2012), meanwhile, exploring education as a whole rather than assessment in particular, articulates an approach based on Fraser's three-dimension theory of social justice (i.e. redistribution, recognition and representation) as articulated in her 2000, 2003 and 2007 papers. Pushing back against educational systems that subordinate certain values, norms and knowledge, Cazden argues that we should address access to education (redistribution), reconsider what is taught (recognition; that is, overcoming the subordination of identities and addressing in particular moment-to-moment teacherstudent interactions), and develop true partnership in decision-making processes (representation). When utilising this concept to inform the development of a socially just approach to assessment, we might also want to include in redistribution an orientation towards addressing inequities in learners’ outcomes.

Nguyen and Walker (2015), criticising the neoliberalist turn in higher education and its resulting emphasis on economic development at the expense of the human and social, promote a social justice approach to assessment that involves 'expanding both student opportunities for individual well-being, but also the formation of agency commitments to advance the common good' (2015, 243). They advocate a human capabilities model that brings together Boud's (2000) theory of sustainable assessment with the capabilities approach to welfare developed by Sen (1999) and Nussbaum (2000). This results in assessment that 'in addition to economic and personal development, emphasises intrinsic learning and the formation of human capabilities and functionings for students to succeed in HE and to have richly human lives as 
constitutive of social justice' (Nguyen and Walker 2015, 246). The four capabilities that assessments should develop in this approach are i) being able to make informed judgements; ii) being reflexive and self-directed learners; iii) having economic opportunities; and iv) being collaborative, connected and responsible towards others.

Finally, both Stowell (2004) and McArthur (2016) critique approaches to assessment based on procedural justice; that is the notion that by making the processes, rules and regulations around assessment as fair and neutral as possible, assessment will be just. These scholars articulate how such approaches fail to address adequately inequities in assessment since they ignore the complex social, political and individual values and judgements attached to these processes, rules and regulations. McArthur then suggests an approach that combines the capability theory of Sen and Nussbaum with the critical theory of Fraser to develop assessment praxis that incorporates both 'the justice of assessment within higher education, and [...] the role of assessment in nurturing the forms of learning that will promote greater social justice within society as a whole’ (McArthur 2016, 967).

\section{Drawing on Universal Design and Culturally Sustaining Pedagogy}

In some ways, McArthur's approach, which sees social justice as both an intrinsic quality of assessment as well as one of its core learning outcomes, can be seen as a conceptual synthesis that incorporates the approaches previously articulated within the work of Hockings, Cazden, and Nguyen and Walker. As such, McArthur's conceptualisation of a social justice approach to assessment provides a key ideational touchstone for our paper. However, at this point in time, McArthur does not articulate how her approach might be achieved, and it remains to be clarified precisely what might best facilitate the realisation of socially just assessment. Further, she argues, 'any notion of assessment for social justice cannot be a prescriptive list of practices or even of set 
base principles’ (2016, 967). While a resistance to addressing processes and principles can be understood in light of criticisms of procedural justice approaches to equality in assessment, we would argue that a flexible and adaptive schema of praxis can be developed to support McArthur's theory, and it is this that the current paper aims to realise.

To extend learning as to how socially just assessment might contribute to more equitable outcomes within higher education, we draw on analogous developments in educational theory in the US. Here, scholars have sought to articulate the ways in which the two conceptual frameworks of Culturally Sustaining Pedagogy (CSP) and Universal Design for Learning (UDL) might be cross-pollinated to provide a vantage point for guiding positive educational change (Alim et al. 2017; Waitoller and King Thorius 2016; Annamma, Connor, and Ferri 2013).

Accordingly, CSP 'seeks to perpetuate and foster - to sustain - linguistic, literate, and cultural pluralism as part of the democratic project of schooling' (Paris 2012, 93). This involves not just making space through the curriculum and pedagogies for cultural diversity, embedding it in what and how we teach, but also encouraging critical reflection on the nature of cultures as well as on their fluidity. Exploring and assessing this in discipline- specific modalities, cultures and societies are seen to be, along with their attendant mores and values, neither pre-determined nor static; further, it is realised that they are also neither universally progressive nor oppressive. To assume as such is again to over-essentialise. The conscious consideration of culture, power and race within the curriculum, then, challenges the notion of norming and homogeneity. There are emerging synergies between this approach and UDL.

Though the core focus of UDL has traditionally been disability, this theoretical perspective contests some of the taken-for-granted assumptions underpinning a wider 
normed approach to higher education provision, which, UDL argues, has resulted in a rather inflexible, excluding, one-size-fits-all curriculum that is disabling: it does not empower all students to reach their potential (CAST 2011). To redress this, UDL advocates three principles of curriculum design: i) provide multiple means of representation (the what of learning); ii) provide multiple means of action and expression (the how of learning); and iii) provide multiple means of engagement (the why of learning). UDL, then, is primarily focused on the accessibility of the curriculum and its assessment. To some extent, in terms of its application to assessment, it also seeks to extend the nature of learning through authenticity of practice and ultimate sustainability of impact.

What both theories have in common is a concern to open up the curriculum: UDL by diversifying how we teach and the methods by which we can evidence learning to enhance accessibility (Fraser’s redistribution); CSP by embedding diversities as exemplified in cultural, social and student identities into what and how we teach to enhance inclusivity (Fraser's recognition). A cross-pollination, then, approximates to the first element of McArthur's social justice approach to education: creating just assessment (although it omits Fraser's representation). CSP's additional aspect of critical reflexivity on the nature of cultures intends to facilitate a better understanding of, and engagement with, diverse societies as well as active engagement with their developments. This is explicitly related to social justice by CSP proponents in that it aims to nurture understanding and agency that will support the active development of justice in society: McArthur's second element.

We must emphasise here that the social justice approach to assessment advocated by McArthur and the cross-pollination of CSP and UDL primarily suggested by Waitoller and King Thorius (2016) are not equivalent. There are of course 
differences. First, as mentioned, a cross-pollinated CSP/UDL does not incorporate the representation aspect of Fraser’s social justice framework: partnership in decisionmaking processes. Second, as of yet, it is unclear as to how such a novel theoretical perspective might be realised in the context of changing assessment policies and practices while adopting a whole organisational approach in higher education. Finally, CSP/UDL is primarily concerned with race and ableism; social justice is both more general and more specific, focusing on the individuality of all students with a strong concern not to essentialise student groups owing to their cultural, ethnic, religious, sexual, neurological or other defined or fluid markers of identity and the contexts within which they coalesce.

The two foci in the latter are not, however, mutually exclusive: a social justice approach to pedagogy and assessment does, at times, require a specific focus providing insight from the particular experiences of individuals and communities who may encounter differing experiences of systemic inequities within higher education. There are occasions, for example, when it is important to explore the particular challenges faced by disabled students, and within this broad categorisation, one may wish to identify particular learning enablers and challenges associated with neurodiversity for instance. Likewise, institutions may wish to strengthen knowledge and capacity about the processes and outcomes that lead to educational experiences that have been racialised and how racialised experiences are different for individuals and groups of students or staff. Nevertheless, where there are foci upon attributes of difference or labels, it is, as the social justice theorists emphasise, important that these do not become essentialised.

The social justice approach to assessment that we advocate is, then, a valuesbased whole-university approach that is at once universal and anticipatory while 
responsive to individual learning requirements, especially for those who may have been disempowered or who traditionally may not have had access to higher education and whose learning outcomes may fall short of other normed privileged cohorts. As mentioned previously, it is but one approach that could be taken under the social justice umbrella, focusing on tackling societal norms, redressing cultural and education dominances and moving to true partnership. In this form, it could perhaps be seen as a step along the path to stronger forms of social justice that look to dismantle systems of oppression and dominant hierarchies, and build participatory democracies.

What follows is an articulation of what such an approach might look like in practice. Drawing on the broader praxis that characterises a cross-pollinated CSP/UDL - with the addition of Fraser's representation element and a balance between a focus on the individual, groups and the whole - we outline a schema of praxis that encapsulates a social justice approach to assessment as well as a framework for organisational change to enable its sustainable development.

What we offer does not aim to perfect assessment. We agree here with McArthur regarding the impossibility of such a task; instead, we hope that it moves towards tackling the codification of cultural, disciplinary and individual norms, values and knowledge hierarchies within and through assessment while also enabling critical reflection on the creation, nature and fluidity - as well as their inextricable connections to society - of these norms themselves.

\section{A social justice approach in action: beginning with UDL}

So what does such assessment praxis look like? We begin by exploring the UDL approach (CAST 2015; CAST 2011. Cf. University of Plymouth (2014) which articulates a similar approach to that of CAST). First, we address the concept of 'multiple means of representation'. In its simplest form, this refers to how assessment 
information is presented in order to allow for maximum clarity of communication. It understands that we process information and knowledge in different ways and so asks for multiple forms of communication, clarification of that which is communicated, and the provision of a range of opportunities to develop comprehension. This has implications not only for how we communicate assessment briefs, expectations and processes, but also for our feedback practices. To what extent, for example, do we provide feedback in different formats, to what extent is our feedback context sensitive building on learner histories and needs - and to what extent do we practice feedforward to support clarification and comprehension?

In their 2015 top ten tips for assessment, CAST also recommends the inclusion of frequent formative assessments and involving learners in their learning journey through engagement with assessment data. Such recommendations go some way though do not fully encapsulate - the notion of assessment literacy; that is the development of students' knowledge, skills and understanding of assessment practices, processes and developments. As Price et al. (2012, 10-11) illustrate in their seminal text, being 'assessment literate' means i) appreciating how assessment relates to learning; ii) understanding the principles of assessment, its criteria and its standards; iii) being skilled in self- and peer-assessment; iv) being familiar with technical approaches to assessment; and v) having the skills to select and apply the most appropriate technique for each task. Developing assessment literacy, then, means we do not assume all students intuitively understand assessment practices and processes; we instead work to ensure they are equally included and supported in their assessment experience and thus enabled to achieve their potential. A UDL approach to the development of assessment literacy would involve students negotiating with educators to realise multiple means and methods of evidencing outcomes. Following reflection, there would 
be a need to modify content, processes and resources where necessary in order to ensure that all learners grasp key knowledge or skills and can evidence this through multiple assessment forms.

Relatedly, the second core principle of UDL 'multiple means of action and expression’ involves providing students with different ways of working with information and content. This means, for instance, providing a range of ways in which students can demonstrate their learning in manners that are most appropriate to assessment tasks. It acknowledges that assessments are often limited to only a few methods according to discipline (for example, essay and exam in Humanities-based subjects) and that these approaches preference those who are best suited to those methods, whilst at the same time disadvantaging others. In using a range of assessment approaches, we work to support all students to be able to best demonstrate their learning. This can be accomplished by providing a range of assessments across a programme of study (ensuring continuity of assessment types across the degree so we are not expecting students to work with a method in their final year with which they are unfamiliar). Additionally, this can be accomplished by utilising assessment methods that design in flexibility in method such as patchwork assessments, an assessment type that has been shown to have the potential to be intrinsically inclusive (Gandhi 2016; Jones-Devitt, Lawton, and Mayne 2016).

The final core attribute of UDL 'multiple means of engagement' involves taking cognisance of student motivation, interest and persistence through recognising, and perhaps self- and peer-assessing, levels of engagement. Ensuring engagement also entails building in assessment and feedback opportunities so that they are timely meaning not just in time but best timed for the student learning journey - and incorporating student choice in assessment method. The latter is not without 
controversy and requires careful planning and support, intertwining it in some ways with the development of assessment literacy articulated above (O’Neill 2017; Keating, Zybutz, and Rouse 2012; Waterfield and West 2006). Indeed, as Keating, Zybutz, and Rouse (2012) found in their introduction of assessment method choice, the provision of space and support for students to become familiar with alternative assessment methods, to understand the requirements and mechanisms of each, and to take control in choosing alternative methods is essential to the success of assessment choice.

Thus, through its three principles, a UDL approach to assessment acknowledges the diversity of student knowledge, skills and prior experience as well as of their different ways of thinking and doing. In so doing, it works to redress inequities in assessment accessibility, making assessment inclusive from point-of-design. In short, it works to create assessment that is, at its heart, socially just.

\section{A social justice approach in action: cross-pollinating}

Of course, UDL is only the first element of our social justice approach to assessment and a possible limitation of it is the presumption that assessment is something educators conduct on students rather than with them. In other words, outwith the incorporation of student choice in assessment method, there can be limitation of student agency. As such, this approach can fall short of Fraser’s third element of social justice: representation through true partnership in decision-making processes. A social justice approach, then, posits learners as agentive co-creators of knowledge with the capacity to determine a diversity of ways in which assessment processes might be designed and implemented. Thus, as argued by Boud and Soler $(2016,403)$, educators need to 'shift discourse away from the notion that assessment is a unilateral act done to students, to assessment that is mutually constructed between learners and assessors/teachers', honouring and empowering learner experience. 
Here, in addition to peer- or self-assessment, we might think of students and staff co-creating assessment schedules, co-producing assessment criteria or even codeveloping assessments themselves. Such a partnership approach does not just build in assessment sustainability, but can also facilitate the development of cultural sustainability. By developing assessment processes with a diverse cohort of staff and students - each with their own varied backgrounds, experiences, identities and understandings - we make space for different ways of thinking, being and doing to be recognised and incorporated. In so doing, we enable assessment that is both inclusive of linguistic, literate and cultural pluralism and that also gives legitimacy to different ways of knowing through primacy of place at point-of-design. We explore this further in two ways: through assessment form and assessment content.

First, assessment form: by this, we mean all aspects of assessment outwith content; for example, assessment methods, marking criteria and assessment processes. As already noted, our dominant Western knowledge production typically focuses on individual rather than communal knowledge and privileges the documented over the oral, the rational over the emotional. It also presents itself as official knowledge that is value-neutral, which dismisses the cultural- and power-related dimensions of knowledge production. This then becomes enshrined through our dominant assessment forms. Through a partnership approach, a range of methods of knowledge production can be acknowledged, reproduced and explored. This goes beyond multiple means of action and engagement, in which a range of assessment types are dictated from a core group of educators who bring with them their cultural, disciplinary and individual biases. Instead, by seriously opening discussion and exploration of different modes of knowledge production (assessment method), different conceptions of what comprises valuable knowledge (marking criteria) as well as the different processes in which 
knowledge can be developed (assessment processes), we bring to the fore not just the cultural pluralism of a diverse student-staff cohort, but also open the discussion to further unfamiliar modes of knowledge production. In so doing, we can both co-design assessment more suited to students’ own backgrounds and cultures, resulting in assessment that works to sustain and equally value different approaches to knowledge production, as well as encourage critical engagement with the concept of knowledge production itself as a social and cultural construct.

The primacy of partnership in this also aims to support students to make judgements on and choices about their learning, taking responsibility for their own learning roles and trajectories. This can powerfully affect the development of student learning in the long term (Waring and Evans 2015). Here we incorporate the important idea of differentiation as a way of reorienting teaching and learning and in so doing we advocate a necessity to begin where individual students may be, rather than with a prescribed, reductionist focus on task and/or outcome. Differentiation through assessment is instead positioned as a vehicle for personalising student learning, whereby an understanding of students' readiness, interests and preferences underpins all learning design, again supporting and enriching a UDL approach that works to maximise assessment accessibility.

Further, we address the concept of assessment content by encouraging the use of content from broad-based knowledge streams, or those that do not typify Western ways of thinking about issues, and this is a core element of CSP. By incorporating critical engagement with cultural-, social- and identity-based diversities through assessment content - through either educator design of assessment content, offering student choice in content or through true partnership in assessment content creation - we work to militate against the privileging of content articulated in the earlier stages of this paper 
and we communicate respect for diverse learners’ experiences and backgrounds. In so doing, we also enrich the multiple means of engagement advocated through a UDL approach, working to increase student motivation, interest and persistence through facilitating recognition between a diverse student cohort and the curriculum. This approach facilitates the development of increased student and staff understandings of differing ways of being, doing and thinking, in turn encouraging colleagues and students to become active agents in the wider social world. It is worth noting that this form of praxis can also challenge and extend cognitive development (Hanesworth 2017; Arkoudis and Baik 2014; Barnett 2011).

A CSP approach, then, explored through the lens of Fraser’s representation, both enriches a UDL approach to assessment, in particular in the elements of multiple means of action/expression and engagement, and broadens beyond neurodiversity to explore the pluralism of the whole student cohort, starting from where - and who - the students are. Such an approach also facilitates critical reflexivity not just on the nature and fluidity of culture, but also on the nature and fluidity of knowledge itself. In so doing, it aims to work towards assessments that equip students and staff to be active agents of social justice, empowering them to help develop a socially just world.

Therefore, a cross-pollination of UDL/CSP as applied to assessment, with the focus of staff-student partnership in assessment design, does, we would argue, provide a schema of praxis that enables actualisation of both elements of McArthur's theory: assessment that is socially just by design and assessment that aims to promote greater social justice within society as a whole. Such a schema requires more than technical competence on the part of the educator. It requires the development of appropriate dispositions and the willingness of educators to confront their own personal 
philosophies, belief systems and dominant ideologies that prevail at discipline, organisational and societal level.

A key strength of such an approach is that it encourages practitioners to review learning and teaching from the perspective of the student and to consider how individual students experience learning. The term personalisation is used here not to depict the individualisation of the curriculum: it is not a matter of tailoring curriculum, teaching and assessment to fit the individual. Rather, it is a question of developing social practices that nurture the unique talents of every student. Personalisation, in this sense, is a collective (and intentional) activity; it is social, not individual. It is also collective in that the values and attitudes that educators and students bring to learning are derived from, and embedded in, a collective organisational ethos that frames all learning, teaching and assessment practices. It is to the development of this organisational ethos that we next turn.

\section{Enabling organisational change: a framework for action}

Focus on organisational change is fundamental to a sustainable social justice approach. As identified by Nicol (2009), such change must reorient thinking and action away from how we might support students to assimilate into existing institutional learning and assessment cultures towards an investigation as to whether, and to what extent, organisational cultures can shift and change to 'embrace the cultures students bring with them' (Evans 2013, 85). As identified earlier in the paper this requires the adoption of robust and purposeful links to social justice, with any proposed change resting on firm, albeit multifaceted, theoretical foundations (2016; McArthur and Huxham 2011). It is through the latter, it has been argued, that organisational change becomes sustainable (Boud and Soler 2016). 
With this in mind, we posit a social justice approach to reviewing assessment at the organisational level that comprises at least four dynamically interacting dimensions. We do so while taking cognisance of the temporal and socio-cultural contexts of individual higher education settings (McArthur and Huxham 2011). The four dimensions are:

(1) Setting of an organisational vision for realising a socially just approach to assessment, and using it to inform the ways that strategic leadership will facilitate changes in existing curriculum and assessment practices.

(2) Developing avenues and mechanisms that encourage involvement by multiple stakeholders, particularly those who have traditionally been marginalised from institutional decision-making processes, including staff and students.

(3) Providing resources of finance, time, technological hardware and software for staff and students, and ensuring there is professional enhancement capacity to engage effectively with developmental changes.

(4) Through praxis, extending the culture of change to incorporate new systems and processes exemplifying minimum standards and best practices for socially just assessments both within the organisation and increasingly affecting wider society.

In terms of the focus upon organisational vision, this is concerned with shifting cultural practices so that strategic leadership becomes more democratic and distributed. It entails a reflexive focus on organisational culture and a moving from recent institutional concerns with extending access for marginalised groups towards highlighting structural inequities in minoritised students' social and learning experiences, and also towards addressing inequities in learning outcomes (Fletcher et al. 2015; Wilson-Strydom 2015). As universities engage in a formative re-evaluation of change management, it is hoped 
that there will be a concomitant reconceptualisation of the nature of leadership so that a 'new approach to leadership (emerges) that goes beyond individual control and management bureaucracy to embrace more sharing and collaboration’ (Jones et al. 2014, 603). This is informed by what Rayner (2009) refers to as 'inclusive leadership': an approach that posits diversity and difference at the fore of the learning community. Through this, leaders become increasingly aware that their remit necessitates conscious efforts to alter organisational culture by relentlessly turning research spotlights on inequities of student experiences and outcomes (Garner and Forbes 2013; Ainscow and Sandill 2010).

Indeed, universities are distinctive learning-focused organisations: their multiple layers of course structure and internal diversities of professional and disciplinary cultures set them apart in terms of complexity (Anderson and Johnson 2006, 8). This complexity is played out through the dynamic interactions between and among the multifarious layers of practice and policy enactment, and the power plays with which they are imbued. In such an environment, cultural change for assessment realignment necessitates the adoption of leadership and change from all quarters: that is to say multiple forms of shared and distributive leadership, including students and drawing on external expertise. This involves commitment and action from senior leaders entailing willingness to set direction - setting minimum standards, incorporating the vision in strategic plans and policies, and facilitating reward and recognition for socially just practice - and then a willingness to negotiate for shared power. This should result in whole-institutional approaches that involve complex and interacting bottom-up interventions with embedded strategic support. Such approaches, as Mountford-Zimdars et al. (2015, iii) argue, 'are likely to have more impact than any one individual approach or policy.' Evidence from recent research also indicates that the role of discipline 
learning and teaching leads is particularly important in this, especially when organisational change is to be embedded within particular discipline-based schools or institutes (Thomas et al. 2017, 110).

A distributed leadership model for the enactment of an organisational vision requires engagement with multiple agents for change: our second key organisational change attribute. This involves a focus upon the nature of action initiation and sustainability. Woods et al. (2004) have suggested that the nature of action ownership and the development of communities of practice (Annala and Mäkinen 2016; Arthur 2016; Tummons 2014) create conditions for enhanced multiple means of action, a core component of the UDL framework (cf. the inclusion of communities of practice as one of UDL's top ten tips for assessment [CAST 2015]). Such communities have the potential to act as core innovators, practitioners and disseminators of socially just assessment practices, and they can reinvigorate existing practices by sharing insights from assessment-focused reflexive praxis and research (Garrow and Tawse 2009). Generative ways of working encourage collective reflective action so that, according to Jones et al. (2014), 'it is difficult to separate leaders from contributors, with the outcome being greater than the sum of the individual contribution.' The complex interplay between policy formation, reconceptualised leadership styles and a focus upon student outcomes is captured by Mountford-Zimdars et al. $(2015,108)$ who argue that:

HEIs should consider embedding their commitment to reducing differentials in progression and attainment in their strategic policy frameworks (e.g. as part of their equality and diversity and learning and teaching strategies) and promote and support a shared understanding of this agenda among senior managers, academics and students. In doing so, HEIs should consider encouraging approaches that view staff, students, and managers as partners learning from each other to enhance outcomes for students. 
The third dimension of our framework for action acknowledges that systematic organisational changes are dependent upon resource availability. A key attribute of this is a commitment to enabling the professional enhancement of all staff, particularly while strengthening strategies to enhance student assessment literacy (Deeley and Bovill 2017; Smith et al. 2013; Price et al. 2012). This strand of action explicitly reveals and seeks to redress injustices of discrimination while also seeking to demystify processes of assessment, both of which can lead to unequal outcomes for students. This may result from both external societal and/or internal contributory factors. The latter may include, for example, unconscious biases which, although 'partially contained by assessment procedures that inhibit their full realisation during marking', without being addressed directly ‘the prejudices, and hence injustices, still remain’ (McArthur 2016, 973-974). Indeed, this was found to be a significant factor in student attainment outcomes when identity markers differed from those of academic staff (Malouff and Thorsteinsson 2016).

Additionally, the technical considerations at each stage of the assessment journey are ripe for consideration in order to strengthen the professional confidence and competence of students and staff to engage effectively with assessment processes while purposefully countering inequities in assessment practices. For example, as argued by Evans $(2013,105)$, the role of written and oral feedback is critical especially for cohorts of students who traditionally have been allocated lower levels of academic attainment and achievement. Evans suggests that several attributes of practice require attention if this is to be addressed: in the first instance, it is critical to interrogate the nature and conceptual underpinning of lecturers' understandings of, and their engagement with, learning and feedback. Further, it is necessary to determine whether the nature of feedback is fit for purpose relative to the task. Finally, Evans suggests that a pivotal 
change axis revolves around the dialogic learning conversations required between students and educators so that that there is a growing convergence of ideas concerning the nature and purpose of feedback and feedforward and a conscious reflection of how these processes interface with attributes of student identity.

Further elucidating this concept, McArthur and Huxham (2011) suggest that, in order to effect whole organisational change, universities need clearly articulated rationales for providing well-informed and well-timed discussions about assessment experiences and outcomes that take place among and between student peers and educators. This rationale is, then, an explicit intention to redress socially unjust and unsustainable imbalances in assessment outcomes. In short, requisite professional enhancement programmes and research projects require a focus upon systemic natures of inequality, the diversities of ways that these are replicated through traditional assessment processes, and the ways that assessment literacies and alternate forms of assessment can interrupt such nefarious practices.

The fourth dimension of the framework is concerned with the ways in which learning from iterative change processes and research outcomes in assessment can be further embedded into the wider community and within cultural practices associated with individual universities and their professional networks. This might mean further developing discipline-specific communities of practice around socially just assessment, incorporating it into institutional and disciplinary conferences and events, developing systems and processes to ensure that socially just assessment features on annual enhancement plans, incorporating into revalidation processes, engaging external examiners with new assessment and feedback policies and practices that follow a social justice methodology, developing toolkits and flowcharts to map its development, and funding collaborative (internal and external) research. In turn, innovations in assessment 
policies and practices can be disseminated more widely to those within and outwith the institution, challenging the taken-for-granted normative procedural forms of traditional assessments that tend to replicate existing inequities, informing and influencing external cultures of practice, and, ultimately, aiming for wholesale sector reform.

\section{Conclusion}

Taken together, we suggest that a focused and dynamic interaction between the four dimensions for organisational change, along with the overarching attributes of a crosspollinated UDL/CSP approach to assessment, provide a proposed typology for designing and implementing assessment policies and practices that comprise one form of social justice, a form that could generate momentum towards stronger approaches to social justice that comprise the dismantling of systems of oppression. We argue for the adoption of an organisation-wide approach since this has the potential to challenge pervasive narratives that norm and essentialise individuals and groups of students who have been marginalised through traditional assessment practices. As argued by Ball (2009), creative movements can disrupt the prevailing order of things by enabling multiple becomings that are collective, dynamic and social. In this way, we believe that true representative partnership working has the potential to redress systemic inequities in assessment outcomes.

Ultimately, there is an ethical imperative to re-envision how organisations address assessment policies and processes that replicate wider societal inequities. Thus, organisational actions are required since, as observed by Chang $(2013,172)$, there are tight interconnections between individual change, institutional change, and social change. Utilising a synergy of critically-aware perspectives, as elucidated in McArthur's work, along with an embedding of CSP and UDL, requisite conditions 
emerge that could enable individuals, courses and universities to reconceptualise their ways of being and doing through the application of socially just assessment practices.

We recognise that the examples provided throughout this paper are emerging and contingent and that they will be experienced in differing ways depending on the influences of discipline specificity and on the interplay between other relevant contextual and socio-cultural factors. However, when adopted and adapted according to such contingencies, we are hopeful that we can strengthen, 'the role of assessment in nurturing the forms of learning that will promote greater social justice within society as a whole’ (McArthur 2016, 967). Ultimately, through proposing cultural shifts in how staff and students actively engage with assessment, we seek to strengthen a valuesbased, sustainable approach that is underpinned by the core principle of respect for individual, economic and cultural difference.

Acknowledgements: We would like to thank both the anonymous reviewers and those who attended an early testing of this paper at the 2017 HETL conference for their helpful comments and suggestions.

\section{References}

Ainscow, M., and A. Sandill. 2010. "Developing Inclusive Education Systems: The Role of Organisational Cultures and Leadership.” International Journal of Inclusive Education 14 (4): 401-416. doi:10.1080/13603110802504903.

Alim, H. S., S. Baglieri, G. Ladson-Billings, D. Paris, D. H. Rose, and J. M. Valente. 2017. "Responding to "Cross-Pollinating Culturally Sustaining Pedagogy and Universal Design for Learning: Toward an Inclusive Pedagogy That Accounts for Dis/Ability".” Harvard Educational Review 87 (1): 4-25. doi:10.17763/1943-5045-86.3.366.

Anderson, D., and R. Johnson. 2006. Ideas of Leadership Underpinning Proposals to the Carrick Institute. Strawberry Hills, NSW: Carrick Institute for Learning and Teaching in Higher Education.

Annala, J., and M. Mäkinen. 2016. "Communities of Practice in Higher Education: Contradictory Narratives of a University-Wide Curriculum Reform.” Studies in Higher Education. Advance online publication. doi:10.1080/03075079.2015.1125877. 
Annamma, S. A., D. Connor, and B. Ferri. 2013. "Dis/Ability Critical Race Studies (DisCrit): Theorizing at the Intersections of Race and Dis/Ability.” Race, Ethnicity and Education 16 (1): 1-31. doi:10.1080/13613324.2012.730511.

Arkoudis, S., and C. Baik. 2014. "Crossing the Interaction Divide between International and Domestic Students in Higher Education.” HERDSA Review of Higher Education 1: 47-62. http://www.herdsa.org.au/herdsa-review-higher-educationvol-1/47-62.

Arthur, L. 2016. "Communities of Practice in Higher Education: Professional Learning in an Academic Career.” International Journal for Academic Development 21 (3): 230-241. doi:10.1080/1360144X.2015.1127813.

Atkinson, D. 2002. Art in Education: Identity and Practice. Dordrecht: Kluwer Academic Publishers.

Ball, A. F. 2009. "Toward a Theory of Generative Change in Culturally and Linguistically Complex Classrooms.” American Educational Research Journal 46 (1): 45-72. doi:10.3102/0002831208323277.

Barnett, P. E. 2011. "Discussions across Difference: Addressing the Affective Dimensions of Teaching Diverse Students about Diversity.” Teaching in Higher Education 16 (6): 669-679. doi:10.1080/13562517.2011.570435.

Boud, D. 2000. "Sustainable Assessment: Rethinking Assessment for the Learning Society.” Studies in Continuing Education 22 (2): 151-167. doi:10.1080/713695728.

Boud, D., and R. Soler. 2016. "Sustainable Assessment Revisited.” Assessment and Evaluation in Higher Education 41 (3): 400-413. doi:10.1080/02602938.2015.1018133.

Bourdieu, P. 1988. Homo Academicus. Translated by P. Collier. Cambridge: Polity Press.

CAST. 2011. Universal Design for Learning Guidelines Version 2.0. Wakefield, MA: National Center on Universal Design for Learning.

CAST. 2015. Top 10 UDL Tips for Assessment. Wakefield, MA: National Center on Universal Design for Learning.

Cazden, C. B. 2012. “A Framework for Social Justice in Education.” International Journal of Educational Psychology 1 (3): 178-198. doi:10.4471/ijep.2012.11.

Chang, M. J. 2013. "Post-Fisher: The Unfinished Research Agenda on Student Diversity in Higher Education.” Educational Researcher 42 (3): 172-173. doi:10.3102/0013189X13486764.

Deeley, S. J., and C. Bovill. 2017. "Staff Student Partnership in Assessment: Enhancing Assessment Literacy through Democratic Practices.” Assessment and Evaluation in Higher Education 42 (3): 463-477. doi:10.1080/02602938.2015.1126551.

ECU (Equality Challenge Unit). 2016. Equality in Higher Education: Statistical Report 2016. Part 2: Students. London: Equality Challenge Unit.

Evans, C. 2013. “Making Sense of Assessment Feedback in Higher Education.” Review of Educational Research 83 (1): 70-120. doi:10.3102/0034654312474350.

Filer, A. ed. 2000. Assessment: Social Practice and Social Product. London: Routledge.

Fletcher, J., C. Bernard, A. Fairtlough, and A. Ahmet. 2015. "Beyond Equal Access to Equal Outcomes: The Role of the Institutional Culture in Promoting Full Participation, Positive Inter-Group Interaction and Timely Progression for Minority Social Work Students.” British Journal of Social Work 45 (1): 120 137. doi:10.1093/bjsw/bct081.

Fraser, N. 2000. “Rethinking Recognition.” New Left Review 3: 107-120. 
Fraser, N. 2003. "Social Justice in the Age of Identity Politics: Redistribution, Recognition, and Participation.” In Redistribution or Recognition: A PoliticalPhilosophical Exchange, edited by N. Fraser and A. Honneth, 7-109. Translated by J. Golb, J. Ingram, and C. Wilke. London: Verso.

Fraser, N. 2007. "Re-framing Justice in a Globalizing World.” In (Mis)Recognition, Social Inequality and Social Justice, edited by T. Lovell, 17-35. Abingdon: Routledge.

Gandhi, S. 2016. "Confessions of an Accidental Inclusivist.” In Equality and Diversity in Learning and Teaching in Higher Education: Papers from Equality Challenge Unit and Higher Education Academy Joint Conferences, edited by P. Hanesworth, 54-69. London and York: Equality Challenge Unit and Higher Education Academy.

Garner, P., and F. Forbes. 2013. "School Leadership and Special Education: Challenges, Dilemmas and Opportunities from an Australian Context." Support for Learning 28: 154-161. doi:10.1111/1467-9604.12033.

Garrow, A., and S. Tawse. 2009. “An Exploration of the Assessment Experiences of New Academics as They Engage with a Community of Practice in Higher Education.” Nurse Education Today 29 (6): 580-584. doi:10.1016/j.nedt.2009.01.013.

Gunn, V., J. Morrison, and P. Hanesworth. 2015. Equality and Diversity in Learning and Teaching at Scotland's Universities: Trends, Perspectives and Opportunities. York: Higher Education Academy.

Hanesworth, P. 2017. “Standardising Diversity Inclusivity.” In Diversität lernen und lehren - ein Hochschulbuch, edited by N. Auferkorte-Michaelis and F. Linde. Leverkusen: Barbara Budrich.

Hargreaves, D. H. 2014. "A Self-Improving School System and Its Potential for Reducing Inequality.” Oxford Review of Education 40 (6): 696-714. doi:10.1080/03054985.2014.979014.

Hatton, K. 2012. "Considering Diversity, Change and Intervention: How the Higher Education Curriculum Looked in on Itself.” Widening Participation and Lifelong Learning 13 (1): 34-50. doi:10.5456/WPLL.13.S.34.

Hockings, C. 2010. Inclusive Learning and Teaching in Higher Education: A Synthesis of Research. York: Higher Education Academy.

Hodkinson, P. 2005. "Learning as Cultural and Relational: Moving Past Some Troubling Dualisms.” Cambridge Journal of Education 35 (1): 107-119. doi:10.1080/0305764042000332524.

Jones, S., M. Harvey, G. Lefoe, and K. Ryland. 2014. "Synthesising Theory and Practice: Distributed Leadership in Higher Education.” Educational Management Administration and Leadership 42 (5): 603-619. doi:10.1177/1741143213510506.

Jones-Devitt, S., M. Lawton, and W. Mayne. 2016. HEA Patchwork Assessment Practice Guide. York: Higher Education Academy.

Keating, N., T. Zybutz, and K. Rouse. 2012. "Inclusive Assessment at Point-OfDesign.” Innovations in Education and Teaching International 49 (3): 249-256. doi:10.1080/14703297.2012.703022.

Leathwood, C. 2005. “Assessment Policy and Practice in Higher Education: Purpose, Standards and Equity." Assessment and Evaluation in Higher Education 30 (3): 307-324. doi:10.1080/02602930500063876.

Litowitz, B. E. 1993. “Deconstruction in the Zone of Proximal Development.” In Contexts for Learning: Sociocultural Dynamics in Children's Development, 
edited by E. A. Forman, N. Minick, and C. Addison Stone, 184-196. Oxford: Oxford University Press.

Lynch, K., and J. Baker. 2005. "Equality in Education : An Equality of Condition Perspective.” Theory and Research in Education 3 (2): 131-64. doi:10.1177/1477878505053298.

Malouff, J. M., and E. B. Thorsteinsson. 2016. "Bias in Grading: A Meta-Analysis of Experimental Research Findings.” Australian Journal of Education 60 (3): 245256. doi:10.1177/0004944116664618.

McArthur, J. 2016. “Assessment for Social Justice: The Role of Assessment in Achieving Social Justice.” Assessment and Evaluation in Higher Education 41 (7): 967-981. doi:10.1080/02602938.2015.1053429.

McArthur, J., and M. Huxham. 2011. Student Engagement Final Report: Sharing Control: A Partnership Approach to Course Design and Delivery. York: Higher Education Academy.

Mountford-Zimdars, A., D. Sabri, J. Moore, J. Sanders, S. Jones, and L. Higham. 2015. Causes of Differences in Student Outcomes. Bristol: HEFCE.

Nguyen, T., and M. Walker. 2015. “'Capabilities-Friendly’ Assessment for Quality Learning.” South African Journal of Higher Education 29 (3): 243-259. doi:10.20853/29-4-504.

Nicol, D. 2009. Transforming Assessment and Feedback: Enhancing Integration and Empowerment in the First Year: Mansfield: Quality Assurance Agency for Higher Education.

Nussbaum, M. C. 2000. Women and Human Development: The Capabilities Approach. Cambridge: Cambridge University Press.

O'Neill, G. 2017. "It's Not Fair! Students and Staff Views on the Equity of the Procedures and Outcomes of Students' Choice of Assessment Methods.” Irish Educational Studies 36 (2): 221-236. doi:10.1080/03323315.2017.1324805.

Paris, D. 2012. "Culturally Sustaining Pedagogy: A Needed Change in Stance, Terminology, and Practice.” Educational Researcher 41 (3): 93-97. doi:10.3102/0013189X12441244.

Price, M., C. Rust, B. O'Donovan, K. Handley, and R. Bryant. 2012. Assessment Literacy: The Foundation for Improving Student Learning. Oxford: The Oxford Centre for Staff and Learning Development.

Rayner, S. 2009. "Educational Diversity and Learning Leadership: A Proposition, Some Principles and a Model of Inclusive Leadership?” Educational Review 61 (4) 433-447. doi:10.1080/00131910903404004.

Ryan, J., and R. Viete. 2009. "Respectful Interactions: Learning with International Students in the English-Speaking Academy.” Teaching in Higher Education 14 (3): 303-314. doi:10.1080/13562510902898866.

Sen, A. 1999. Development as Freedom. Oxford: Oxford University Press.

Smith, C. D., K. Worsfold, L. Davies, R. Fisher, and R. McPhail. 2013. “Assessment Literacy and Student Learning: The Case for Explicitly Developing Students 'Assessment Literacy'.” Assessment and Evaluation in Higher Education 38 (1): 44-60. doi:10.1080/02602938.2011.598636.

Stowell, M. 2004. "Equity, Justice and Standards: Assessment Decision Making in Higher Education.” Assessment and Evaluation in Higher Education 29 (4): 495-510. doi:10.1080/02602930310001689055.

Thomas, L., M. Hill, J. O’Mahony, and M. Yorke. 2017. Supporting Student Success: Strategies for Institutional Change. London, Leicester and York: Paul Hamlyn Foundation, Action on Access, Higher Education Academy. 
Tummons, J. 2014. "Learning Architectures and Communities of Practice in Higher Education.” In Theory and Method in Higher Education Research II (International Perspectives on Higher Education Research, Volume 10), edited by J. Huisman and M. Tight, 121-139. Bingley: Emerald Insight.

University of Plymouth. 2014. 7 Steps to Inclusive Assessment. Plymouth: University of Plymouth.

Waitoller, F. R., and K. A. King Thorius. 2016. “Cross-Pollinating Culturally Sustaining Pedagogy and Universal Design for Learning: Toward an Inclusive Pedagogy That Accounts for Dis/Ability.” Harvard Educational Review 86 (3): 366-389. doi:10.17763/1943-5045-86.3.366.

Waring, M., and C. Evans. 2015. Understanding Pedagogy: Developing a Critical Approach to Teaching and Learning. Abingdon: Routledge.

Waterfield, J., and B. West. 2006. Inclusive Assessment in Higher Education: A Resource for Change. Plymouth: University of Plymouth.

Wilson-Strydom, M. 2015. "University Access and Theories of Social Justice: Contributions of the Capabilities Approach.” Higher Education 69 (1): 143-155. doi:10.1007/s10734-014-9766-5.

Woods, P., N. Bennett, J. A. Harvey, and C. Wise. 2004. "Variables and Dualities in Distributed Leadership: Findings from a Systematic Literature Review.” Educational Management Administration and Leadership 32 (4): 439-457. doi:10.1177/1741143204046497. 